\title{
Intelligent Algorithm based Maximum Power Point Tracking of Photovoltaic Solar Pump
}

\author{
B.Hari Sankar Reddy $^{1^{*}}$, K. Nagabhushanam ${ }^{2}$ \\ ${ }^{l}$ PG Student, Dept Of EEE, JNTUCEA, Anantapuram, Andhra Pradesh, India. \\ ${ }^{2}$ Assistant Professor Dept. Of EEE, JNTUCEA, Anantapuram, Andhra Pradesh, India.
}

*Corresponding Author: B.Hari Sankar Reddy, PG Student,Dept Of EEE, JNTUCEA, Anantapuram, Andhra Pradesh, India.

\begin{abstract}
Particle Swarm Optimization Maximum Power Point Tracking (PSOMPPT) controller are subjected to boost converter for optimal switching angle. Solar energy given by photovoltaic cells which is fabricated by different material like silicon and combinations of cells is known as solar panel. Boost converter to supply to constant input voltage to solar pump from photovoltaic module. PV modules have crest power dependent on temperature and irradiance by naturally occurring in atmosphere.PSO intelligent dependent algorithm to perceive a solution to a development problem in search space. PSOMPPT based controller shows good response with high power output for modeling to nonlinear system as PV modules. A comprehensive simulation of the advanced method has been simulated in Matrix laboratory. The simulation result exhibits that this design should be essentially perceive in practical applications like PMDC pump.
\end{abstract}

Keywords: Particle Swarm Optimization Maximum Power Point Tracking (PSOMPPT); ANFIS; Boost converter; PMDC pump; PV System.

\section{INTRODUCTION}

The burning of fossil fuels to produce electricity is one of the largest sources of $\mathrm{CO}_{2}$ emissions. Solar PV system is of more interest and most promising source of future demand. In future will be all fossil fuels are disappear because more then used we needed. So we preferred to use renewable energy sources have free of cost and available in nature. Here taken source of solar energy becomes most reliable source, clean and pollution free and produced electrical energy by using photo voltalic cells. PV cells made of silicon material manufactured by different stages. These PV panel requested to install in roof tops of house and porticos of buildings. The power acquired from the PV panel is mainly contingent on atmospheric conditions. PV panel efficiency is very low .To enhance the efficiency of pv system become used different tracking systems. To obtained crest power of pv module from source to load using tracking system, in crest with tracking is known as maximum power point tracking (MPPT) controller.

Single junction solar cells having large band gap of fleck results a less amount of energy produced. Proposed module multi junction [1],[2] solar cells having haughty energy band gap to develop maximum energy. Based Upon links classified into two types of cells there lateral multiple junction solar cells and vertical multi junction solar cells. Vertical multi junction cell get extravagant open circuit voltage and expertise agrees with single junction solar cell and potential to get majority beneficial efficiciency by using material placements. Solar cells normally continent on expert diffraction process. Number of cells connected series of multiple strings [4] is tied in parallel [3] to the solar panel. The power output of solar cell swinging with respect to temperature and irradiation so MPPT controller needed.

MPPT are used to select the operating point by the load, these are divided into three category. Prime category shown as traditional class like a Incremental Conductance and Perturb \& Observe method. The demerit of this group is its stagnant tracking ability, study state oscillation at Maximum power point (MPP) and decrees competence. To overcome drawbacks soft evaluating techniques are involved. The techniques [5] that are merged in this category are the Evolutionary Algorithms, Fuzzy 
and Neural Network. These groups also have some defects because of a few entanglements like it requires periodic training and it utilizes more memory will become difficult to develop in bio inspired methods. The final category shown under the type of augmentation computing, Particle Swarm Optimization, Bacterial foraging algorithm, Ant colony optimization and Genetic Algorithm.

Advantages and disadvantages of different MPPT techniques (adopted from [6]) Table 1:

\begin{tabular}{lllllll}
\hline$\#$ & Tracking methods & AD & Sensors & Speed & Stability & Periodic tuning \\
\hline 1 & Constant voltage & A & V & Fast & Not stable & Yes \\
2 & Open-circuit voltage & A & V & Fast & Not stable & Yes \\
3 & Perturb and observe & AD & V\&C & Slow & Not stable & No \\
4 & Linear reoriented coordinates & D & V\&C & Slow & Stable & No \\
5 & Curve-fitting & D & V & Fast & Not stable & Yes \\
6 & dPidV or dP/di feedback control & D & V\&C & Slow & Stable & No \\
7 & Incremental conductance & D & V\&C & Slow & Stable & No \\
8 & Fuzzy logic control & D & V\&C & Very fast & Very stable & No \\
9 & Neural network & D & V\&C & Very fast & Very stable & No \\
10 & Biological swarm chasing algorithm & D & V\&C & Very fast & Very stable & No \\
\hline
\end{tabular}

To increase output power and decrease the cost of PV system, it is required to operate PV panels at PSO. The power output characteristics mostly depend on solar irradiations and cell temperature variations. With the objective of achieving the much power, the output is collinear and depends upon temperature and irradiance conditions. They are clean, naturally replenished, no greenhouse gases, and don't affect human health. Present days PV system became more popular the rapid growing markets due to low maintained cost, the high level of investments involved, and the technological progress.

\section{Modeling Characteristics of PV Module}

Mathematical modeling very crucial part of to design to any system. Here pv module modeling needs a matlab software and first develop a mathematical equation, after simulink model diagram developed. In pv module number of cells connected series to increase the voltage, if parallel connected increase current. if want to change any parameter in whole module is easily in simulation. In this modeling parameters unique and output waveforms are did not analyzing to other models [6]. In practical pv module modeling depends some factors like voltage, current, wattage, irradiation, location, efficiency of battery, dust level of working environment, and temperature. In this parameters help to improve performance of system. Below equations [7] to determined to output power.

$$
\begin{aligned}
& \mathrm{I}=\mathrm{N}_{\mathrm{p}} * \mathrm{I}_{\mathrm{pv}}-\mathrm{N}_{\mathrm{p}} * \mathrm{I}_{\mathrm{s}}\left[\exp \left(\frac{q(V+R s I)}{N s K s T}\right)-1\right]-\frac{V+R s I}{R p} \\
& \mathrm{I}_{\mathrm{pv}}=\left[\mathrm{I}_{\mathrm{sc}}+\mathrm{K}_{\mathrm{i}}\left(\mathrm{T}-\mathrm{T}_{\mathrm{ret}}\right)\right]^{*} \mathrm{G} \\
& \mathrm{Ik}_{\mathrm{s}}=\mathrm{I}_{\mathrm{rs}}\left(\frac{T}{T r e f}\right)^{3} \exp \left[\mathrm{q} * \mathrm{Eg} \frac{\frac{1}{T r e t}-\frac{1}{T}}{\mathrm{Ka}}\right] \\
& \mathrm{I}_{\mathrm{fs}}=\frac{I s c}{\exp \left[\frac{q V o c}{N s K a T}\right]-1}
\end{aligned}
$$

$I_{p v}$ is photocurrent, $I_{s}$ is reverse saturation current, q electron charge $\left(1.602 * 10^{-19} \mathrm{c}\right), \mathrm{k}$ Boltzmann's constant $\left(1.38^{*} 10^{-23} \mathrm{~J} /{ }^{0} \mathrm{~K}\right), \mathrm{T}$ working temperature of cell $\left({ }^{0} \mathrm{~K}\right), \mathrm{N}_{\mathrm{P}}$ parallel connected cells, $\mathrm{N}_{\mathrm{s}}$ series connected cells, a ideality factor of diode, $\mathrm{K}_{\mathrm{i}}$ cell short circuit current temperature coefficient at STC, $\mathrm{T}$ working temperature of cell, Tref reference temperature of cell, $\mathrm{G}$ irradiance of solar $(\mathrm{KW} / \mathrm{m} 2) \mathrm{m}$, Irs reverse saturation current, Eg energy band gap semiconductor in cell(1.1ev). The V-I characteristics of a PV modules are given by Eq [7]

$$
\mathrm{I}=\mathrm{N}_{\mathrm{par}} * \mathrm{I}_{\mathrm{pr}}-\mathrm{N}_{\mathrm{par}} * \mathrm{I}_{\mathrm{s}}\left[\exp \left(\frac{q\left(\mathrm{~V}+\mathrm{RsI}\left(\frac{\mathrm{Nser}}{\text { Npar }}\right)\right)}{\text { NserKaT }}\right)-1\right]-\frac{V+R s I\left(\frac{\text { Nser }}{\text { Npar }}\right)}{R p\left(\frac{\text { Nser }}{\text { Npar }}\right)}
$$

Here Npar is number of cells are linked in parallel in module; Nser is the number cells are linked series in the module. In this module 27 multi crystalline silicon cells are arranged in series to increase 
in voltage to get the $100 \mathrm{w}$ power as a output. below shown table 2 selected required parameters .

Table2. Datasheet of KC100GTS PV module [7]

\begin{tabular}{|l|l|}
\hline variable & value \\
\hline$P_{\max }$ & $100 \mathrm{~W}$ \\
\hline$V_{\max }$ & 17.3 \\
\hline$I_{\max }$ & 4.6 \\
\hline$I_{\mathrm{se}}$ & 5 \\
\hline$V_{\mathrm{oc}}$ & 21.9 \\
\hline Temperature coefficient of Voc & $-1.23^{*} 10^{-1} \mathrm{~V} /{ }^{\circ} \mathrm{c}$ \\
\hline Temperature coefficient of Ise & $3.18 * 10^{-3} \mathrm{~A} /{ }^{\circ} \mathrm{c}$ \\
\hline
\end{tabular}

Fig. 1 shows $R_{p}$ model for single diode which described by Eqs. (1)-(4) for simulation.

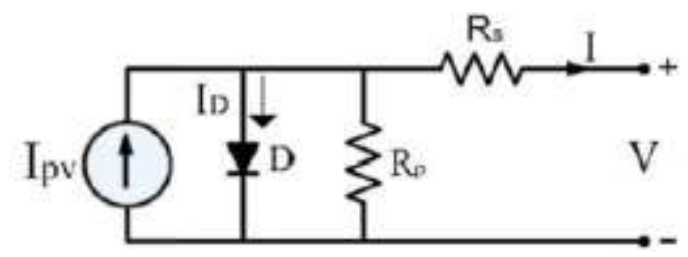

Fig1. Single diode $R_{P}$ model

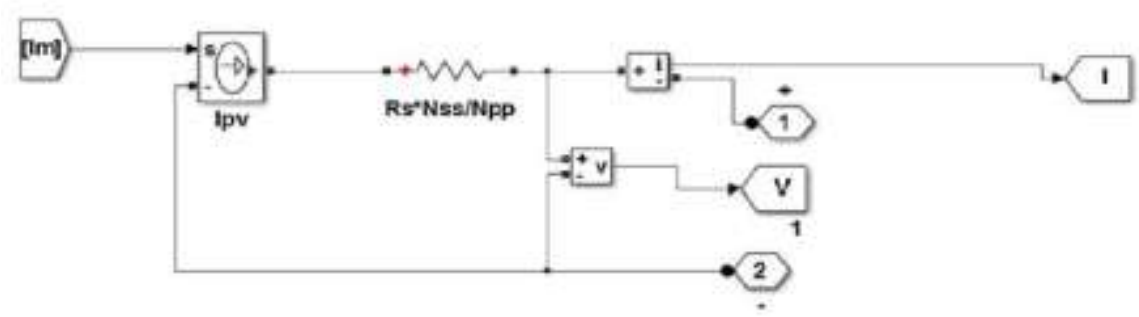

Fig2. PV module circuit model.

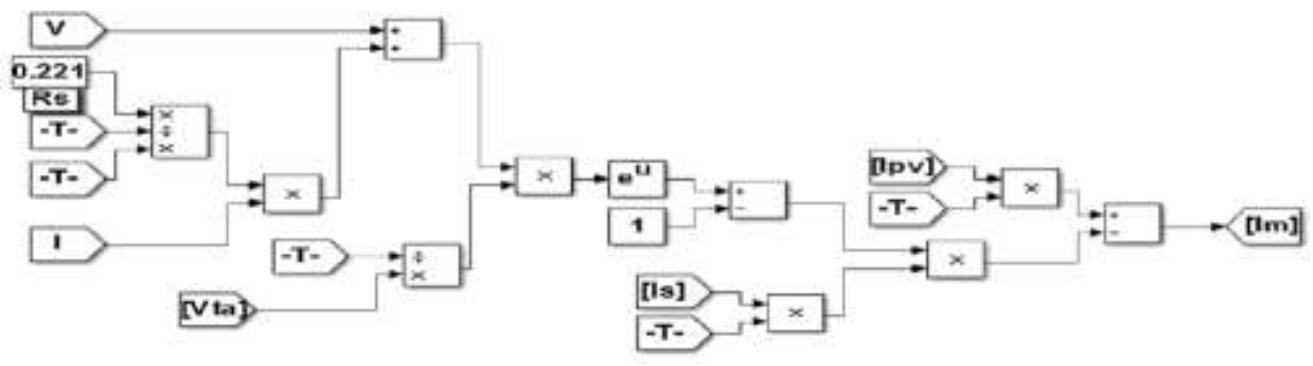

Fig3. module current simulink model

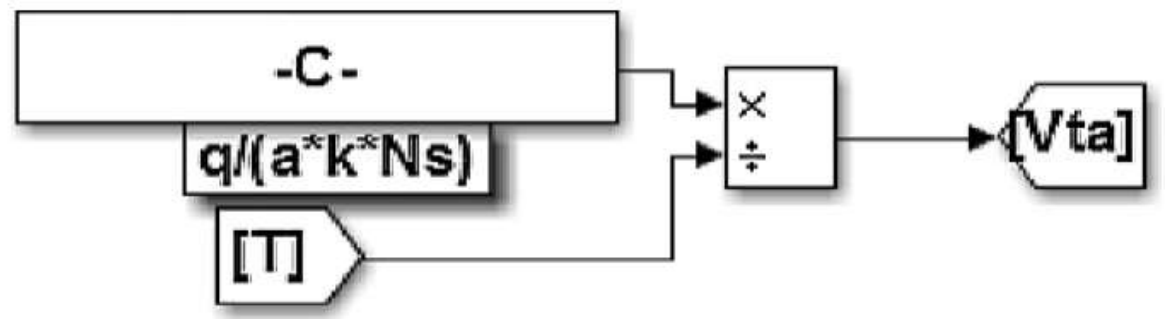

Fig4. Vta simulink model

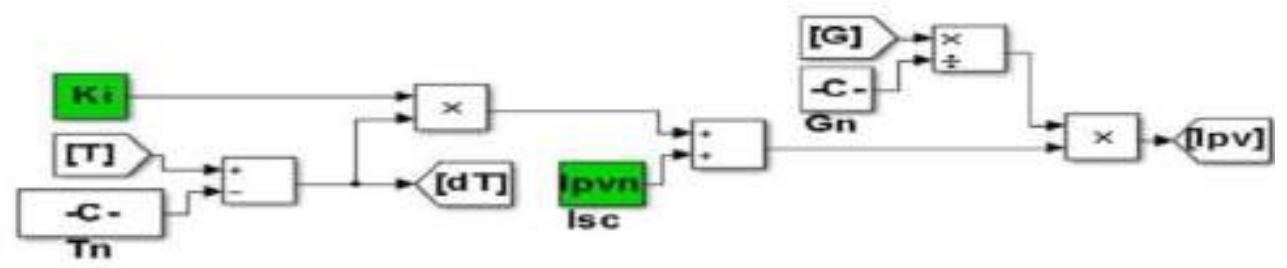

Fig5. photocurrent simulink model

International Journal of Research Studies in Electrical and Electronics Engineering (IJRSEE) Page | 25 


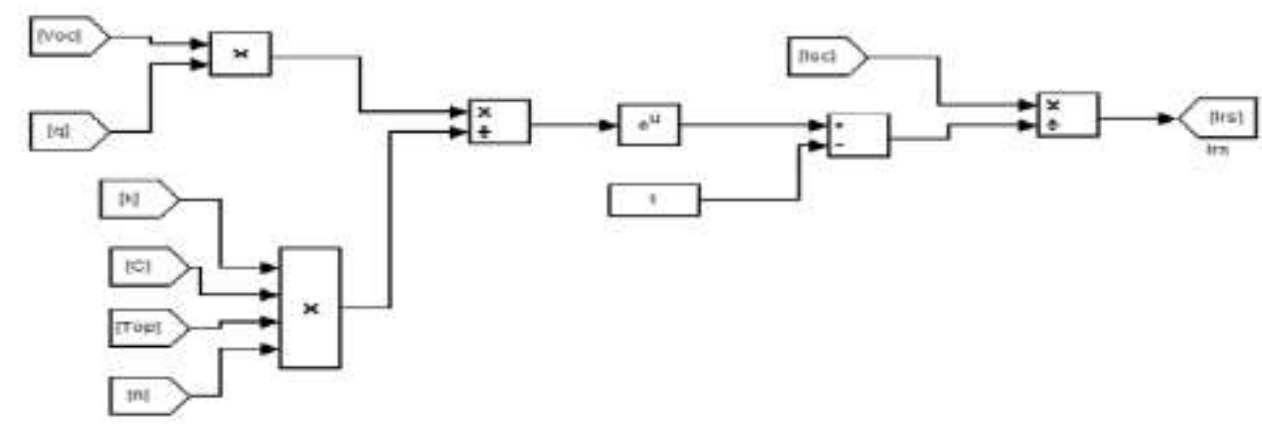

Fig6. Reverse saturation current simulink model

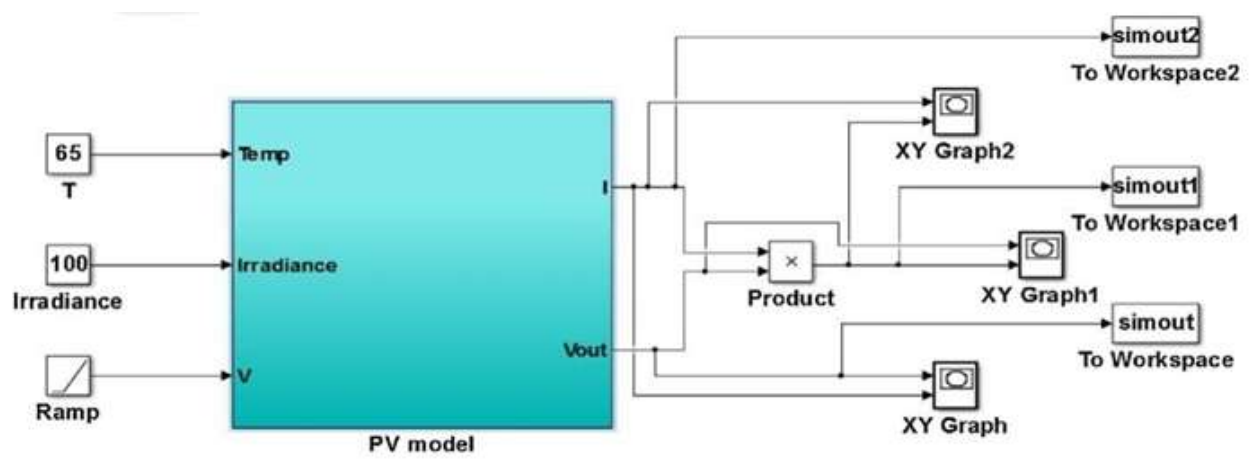

Fig7. PV module

Fig 6 shows pv module operated different temperature and irradiations.fig $(7,8) \mathrm{P}-\mathrm{V}$ curves drawn at the constant temperature $\left(25^{\circ} \mathrm{c}\right)$ and different irradiation level (300-1000)respectively.
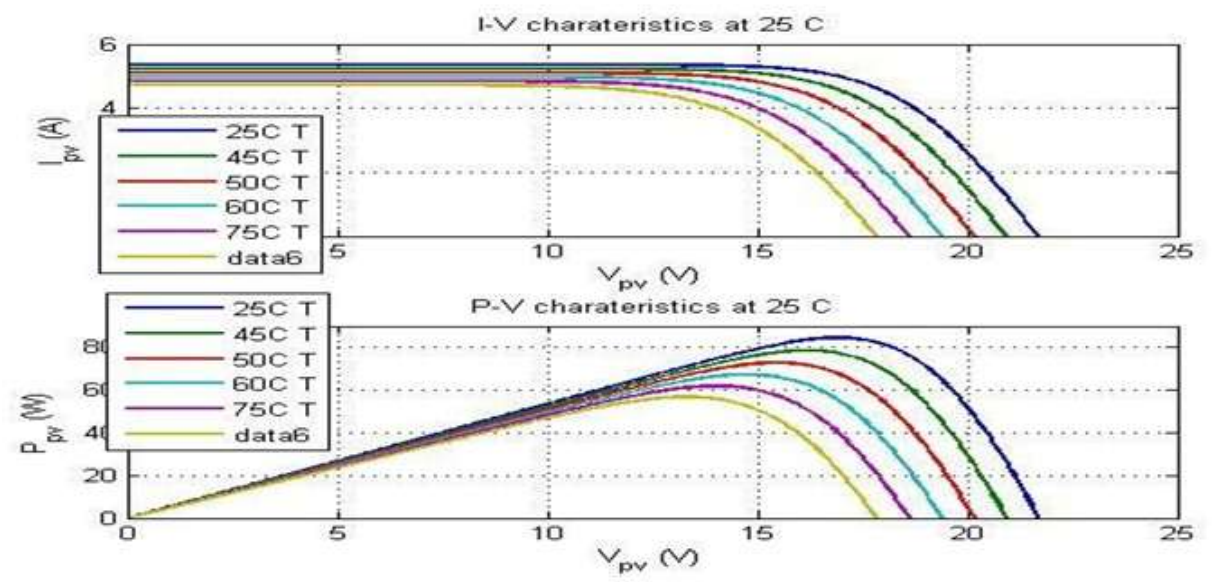

Fig7. $P-V$ and I-V characteristics of PV Module at various temperature

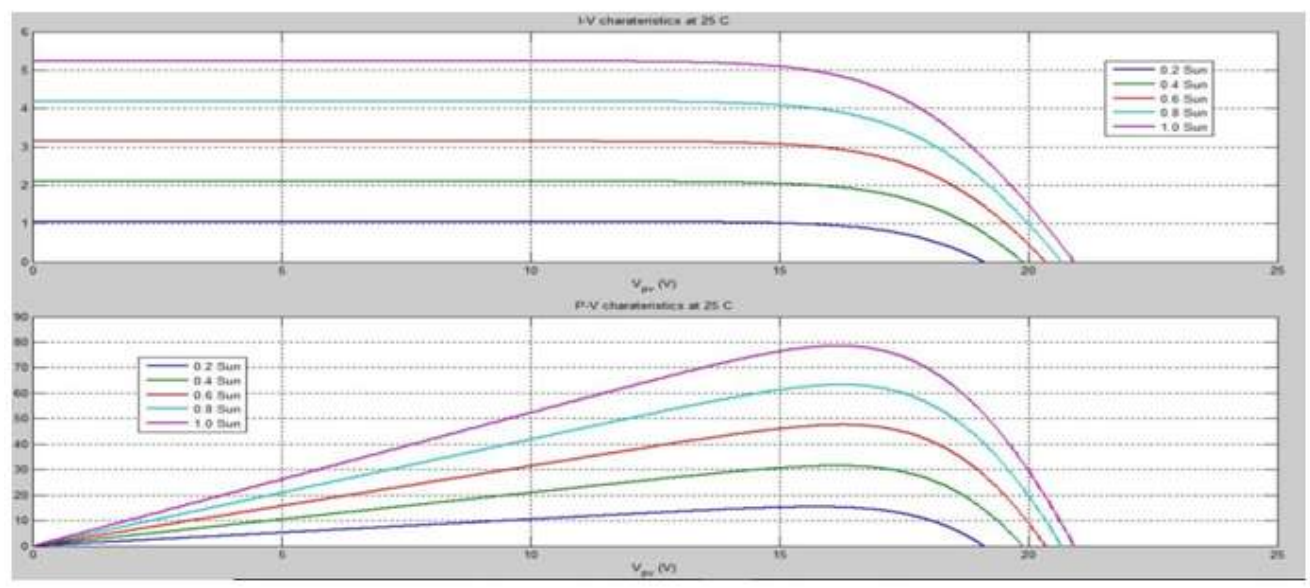

Fig8. $P$-V and I-V characteristics of PV module at various irradiation 


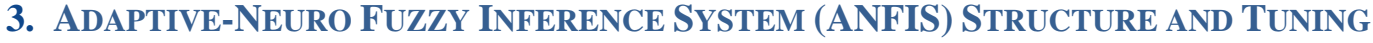

ANFIS is an artificial intelligent system, which is having amalgamation of fuzzy logic and neural networks. In this model taking two inputs like temperature, irradiation and gives power at crest value[9]. The output achieved by using Sugeno type optimization method depending on rule based and input membership function has a gauss method. ANFIS used as modeling, controlling and universal estimator.

The structure of ANFIS consists of five layers, The function of each layer is presented as follows [10].

In which the task of each layer is as follows

- fuzzy layer

- .fuzzification layer

- Inferences process layer

- defuzzification layer

- Output layer

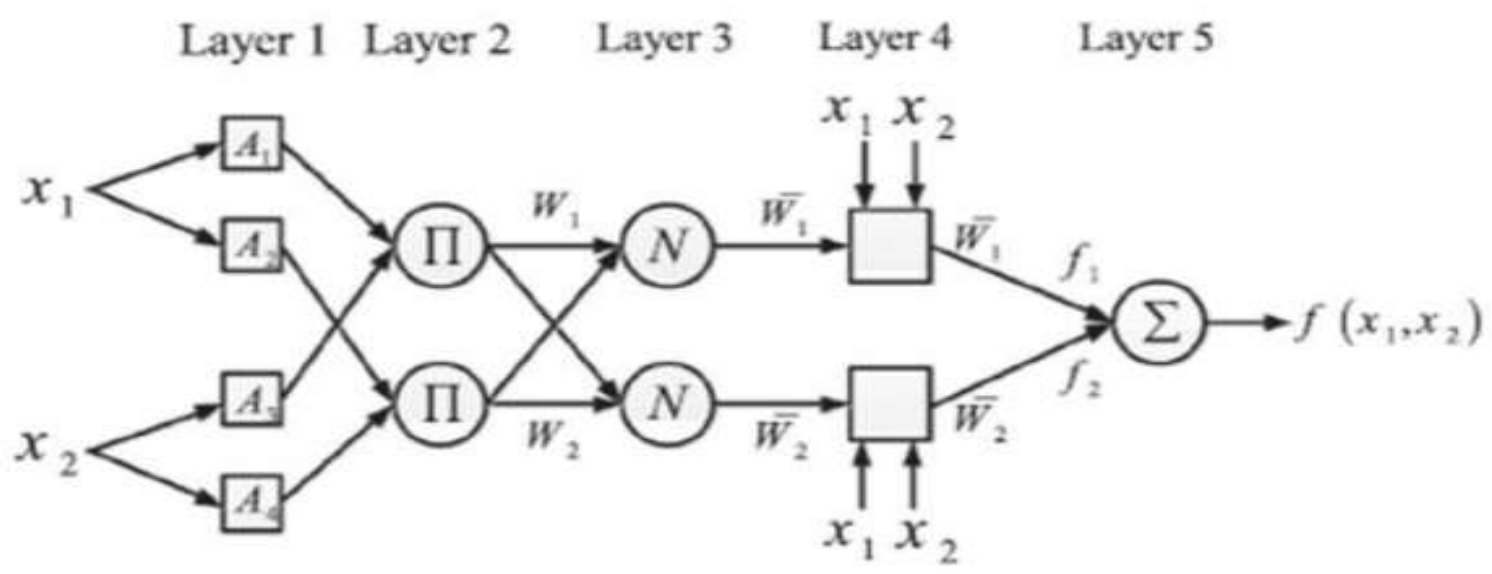

Fig9. ANFIS Structure

Layer1: In this layer output fuzzy values as given input values and membership function Ai at each node. Output of i-th node layer1 given by eq(6).

$\mathrm{O}_{\mathrm{i}, 1}=\mu_{\mathrm{Ai}}\left(\mathrm{x}_{1}\right)$

$\mathrm{O}_{\mathrm{i}, 1}$ the output of the $\mathrm{i}$-th node of layer $1, \mathrm{~A}_{\mathrm{i}}$ is a linguistic variable related with this node. System input of each node $\left(\mathrm{x}_{1}\right)$.

Layer 2: fuzzification layer the output of this layer produces the weights of the membership functions multiplication of their inputs. For example,

$\mathrm{W}_{2}=\mathrm{A}_{2}\left(\mathrm{x}_{1}\right) * \mathrm{~A}_{4}\left(\mathrm{x}_{1}\right)$

Layer 3: inferences process layer produces the rule based individual weight of network is standardized by the adding of the total weights according to Eq.

$\bar{W}=\frac{W k}{\sum_{i-1}^{n} w i}$

Layer 4: In this layer defuzzification of the outputs is achieved, the output of the nodes in this layer is as

$\mathrm{O}_{\mathrm{i}}=\bar{W} i * f i=\bar{W} i *\left(\mathrm{p}_{\mathrm{i}} \mathrm{x}_{1}+\mathrm{q}_{\mathrm{i}} \mathrm{x}_{2}+\mathrm{r}_{\mathrm{i}}\right)$

Layer 5: The output layer determine the ultimate output of the controller as Eq.

$$
\mathrm{f}\left(\mathrm{x}_{1}, \mathrm{x}_{2}\right)=\sum_{i} \bar{w}_{\mathrm{I}}
$$




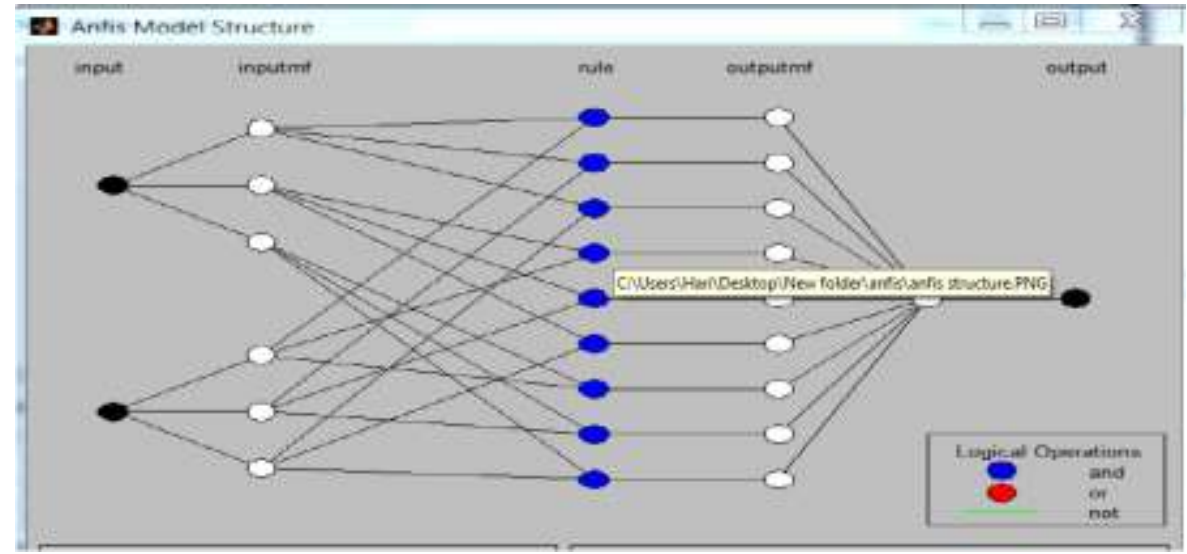

Fig10. ANFIS structure generated by MATLAB

\section{Selection of Network Parameters and Determination of Training and Testing Data}

ANFIS model applied to a input membership function set of data represented in graphically(guess) method, multiplication of some weights, written in rule based, normalized the weights of parameters and final output shown in surface views (3D view).the output errors are throw away to generate important parameters by using back propagation algorithm. The direction parameters modify using sugeno fuzzy inference system by using ANFIS controller.

\section{Input Membership Function Representation}
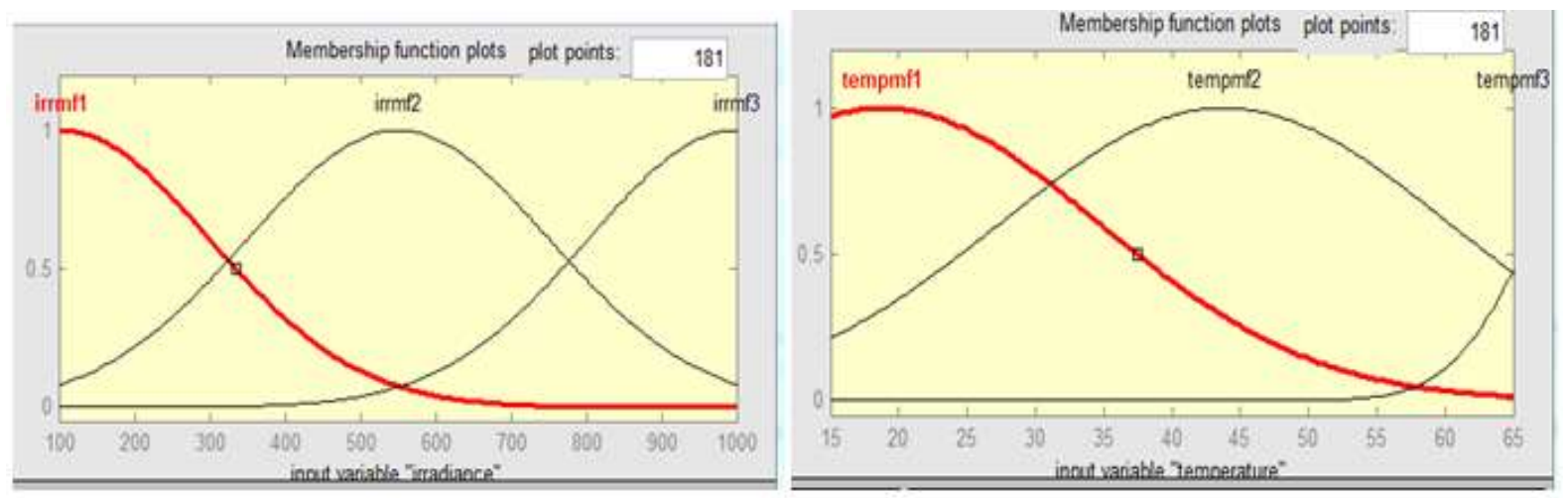

\section{Rulebased Representation}

1. If (irradiance is irrmf1) and (temperature is tempmf1) then (power is powmf1) (1)

2. If (irradiance is irrmf1) and (temperature is tempmf2) then (power is powmf2) (1)

3. If (irradiance is irrmf1) and (temperature is tempmf3) then (power is powmf3) (1)

4. If (irradiance is irrmf2) and (temperature is tempmf1) then (power is powmf4) (1)

5. If (irradiance is irrmf2) and (temperature is tempmf2) then (power is powmf5) (1)

6. If (irradiance is irrmf2) and (temperature is tempmf3) then (power is powmf6) (1)

7. If (irradiance is irrmf3) and (temperature is tempmf1) then (power is powmf7) (1)

8. If (irradiance is irrmf3) and (temperature is tempmf2) then (power is powmf8) (1)

9. If (irradiance is irrmf3) and (temperature is tempmf3) then (power is powmf9) (1)

\section{Surface \& Rule Viewers}
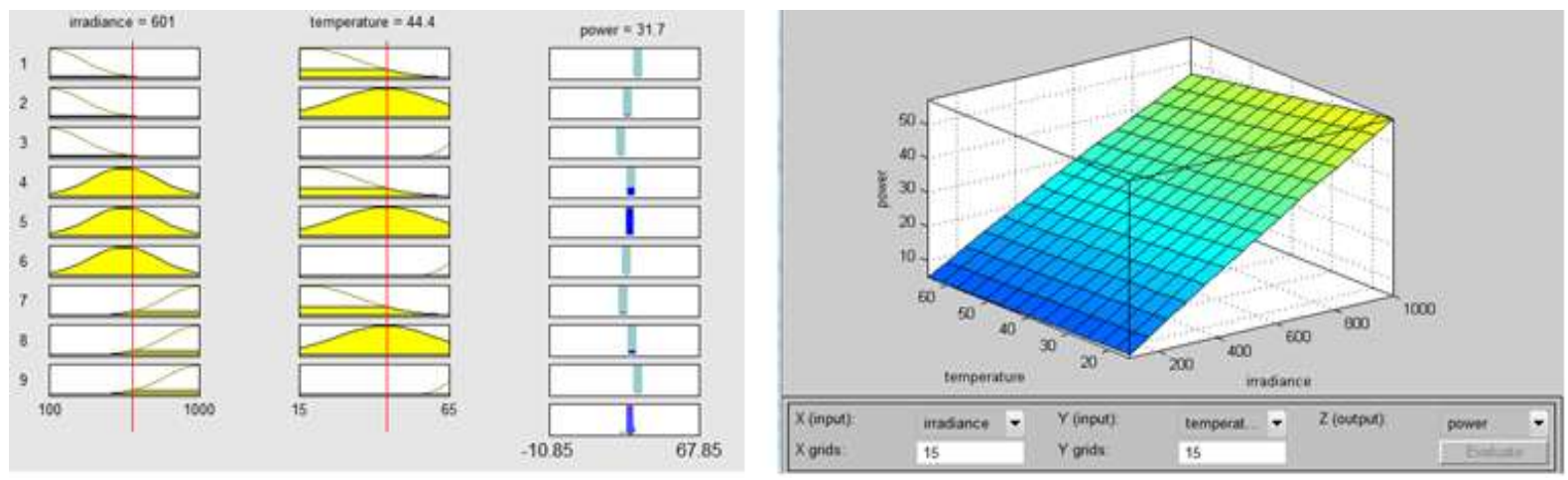

International Journal of Research Studies in Electrical and Electronics Engineering (IJRSEE) Page $\mid 28$ 
Table3. Sampling Data Sheet

\begin{tabular}{|c|c|c|c|}
\hline Number & Irradiance $\left(\mathrm{W} / \mathrm{m}^{2}\right)$ & Temperature $\left({ }^{\circ} \mathrm{C}\right)$ & Power output $(\mathrm{W})$ \\
\hline 1 & 500 & 15 & 740.5256 \\
2 & 500 & 20 & 74.1192 \\
3 & 500 & 25 & 727.7175 \\
4 & 500 & 30 & 721.3214 \\
5 & 500 & 35 & 714.9322 \\
6 & 500 & 40 & 708.5511 \\
7 & 500 & 45 & 702.1794 \\
8 & 500 & 50 & 795.8187 \\
9 & 500 & 55 & 789.4703 \\
10 & 500 & 60 & 783.1359 \\
11 & 500 & 65 & 776.8174 \\
\hline
\end{tabular}

ANFIS model taken two inputs like temperature, irradiance and gives crisp power output by using hybrid optimization which have least square and back propagation based on sugeno type inference system. The range of temperature $\left(15-65^{\circ} \mathrm{c}\right)$ and irradiance $\left(100-1000 \mathrm{w} / \mathrm{m}^{2}\right)$.

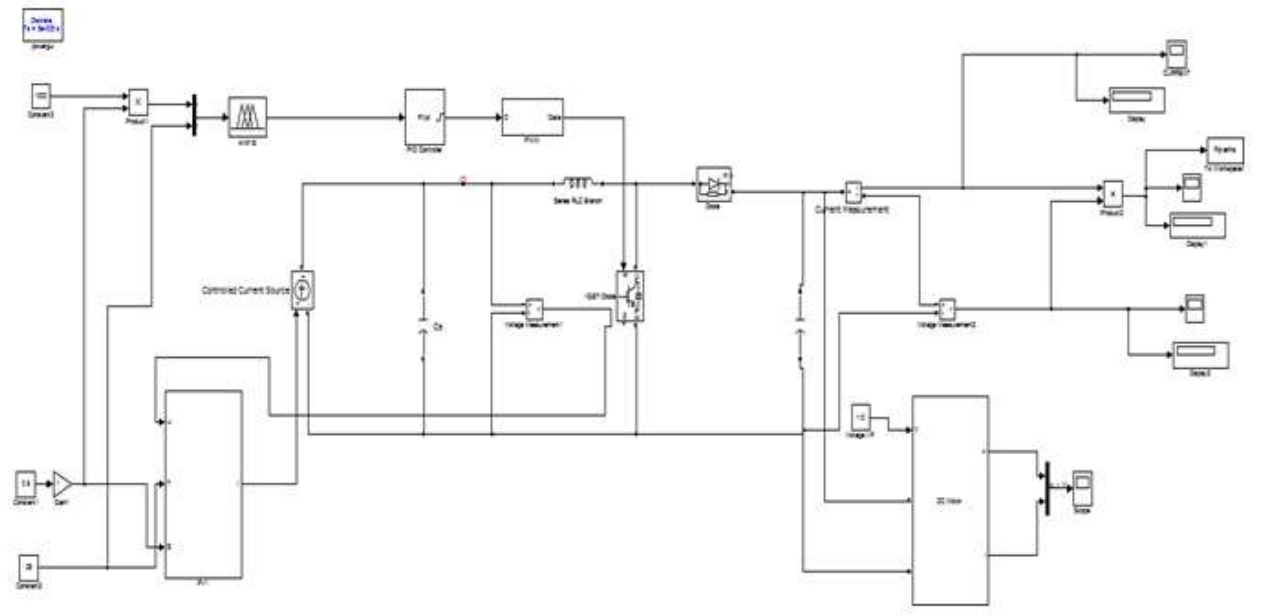

Fig11. Simulink of ANFIS MPPT system with DC motor pump load

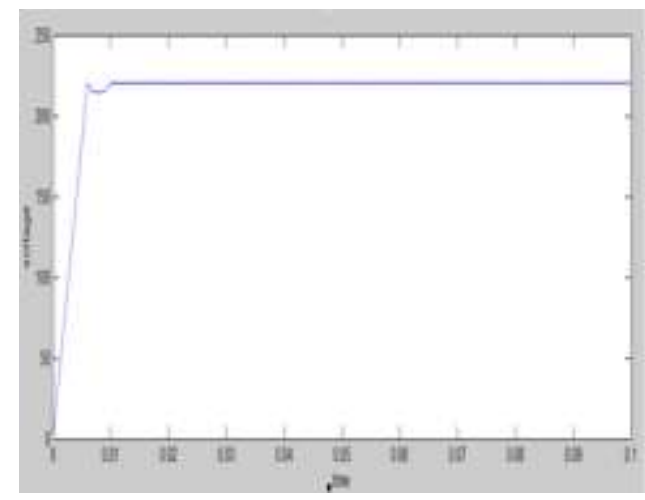

Fig12. Voltagewaveform Using ANFIS

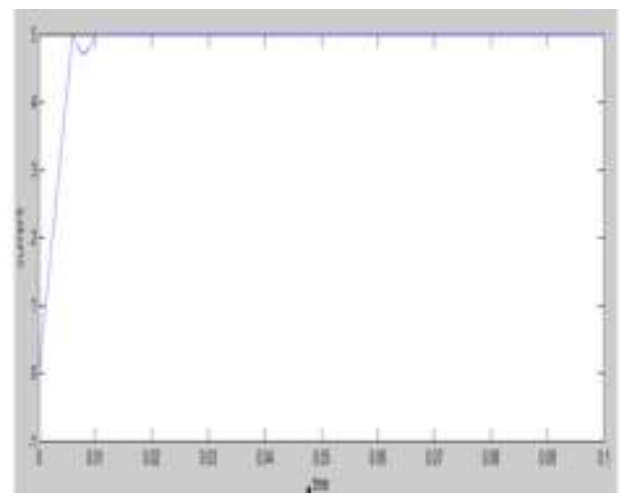

Fig13. Current Waveform Using ANFIS

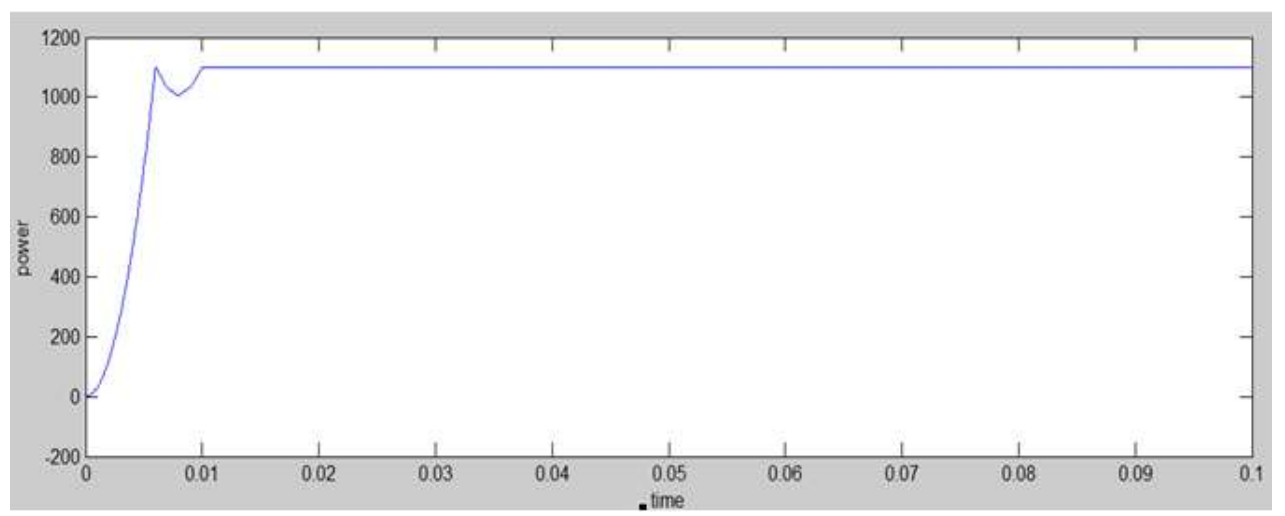

Fig14. Power output waveform using ANFIS 
Table4. Pump performance using ANFIS at different irradiance levels and constant temperature.

\begin{tabular}{|l|l|l|l|l|}
\hline Irradiance $\left(\mathrm{W} / \mathrm{m}^{2}\right)$ & Temperature $\left({ }^{\circ} \mathrm{C}\right)$ & Motor speed $(\mathbf{r} . \mathbf{p} \mathbf{m})$ & Pump torque $(\mathrm{N})$ & Load power $(\mathrm{W})$ \\
\hline 1000 & 25 & 1215 & 5.854 & 1100 \\
\hline 900 & 25 & 1125 & 5.691 & 1050 \\
\hline 800 & 25 & 1091 & 5.475 & 995.5 \\
\hline 700 & 25 & 1042 & 5.171 & 814.6 \\
\hline 600 & 25 & 966 & 4.72 & 798 \\
\hline 500 & 25 & 950 & 4.073 & 645.2 \\
\hline 400 & 25 & 889 & 3.294 & 579.4 \\
\hline 300 & 25 & 815 & 2.475 & 431.5 \\
\hline
\end{tabular}

\section{Particle Swarm Optimization (PSO) Structure and Programming}

PSO was first introduced by Kennedy and Eberhart to optimize the problem in search space. It is an intelligent, stochastic and population based algorithm. In this algorithm first invented related on community behavior of animals like group of fish and flocks of birds pervasive for their food. The flock is usually designed by particles in multidimensional that we have position and velocity. Each particle remain on updating itself by differentiate it to the optimal position up to getting the global best position .The Fitness of particle denoted by best value is known as global best and it leads to other individual particles [18]. PSO algorithm contains some tuning parameters that mostly influence the performance of algorithm stated as the exploration -exploitation tradeoff exploration to test the various region and located best solution. PSO very easy concept and efficient compared to other iterative algorithms. It has less iteration, easy recognition and fast convergence.

\section{Global Best ( $\mathbf{g}_{\text {best) }}$ PSO:}

It is method where the position of each particle is influence by best -fit particle in the whole swarm it is used star social network topology where the social statics achieved from all particles in whole swarm.

\section{Local Best ( $\left.\mathbf{l}_{\text {best }}\right)$ PSO:}

In the method allows each particle to be achieved by the best-fit particle chosen from its neighborhood and it represent the ring social topology. Best position of particle had in neighborhood found from initialization across time $(\mathrm{t})$.

In this algorithm[12]given below, The position of particle represent $y_{i}$ changing randomly, velocity represent letter $a_{i}$ initially 0 value started. Below equation taken from [19]

$$
\mathrm{a}_{\mathrm{i}}^{\mathrm{t}+1}=\mathrm{sa}_{\mathrm{i}}^{\mathrm{t}}+\mathrm{z}_{1} \text { rand } \mathrm{O}\left(\text { pbest }_{\mathrm{i}}^{\mathrm{t}}-\mathrm{y}_{\mathrm{i}}^{\mathrm{t}}\right)+\mathrm{z}_{2} \text { rand } \mathrm{O}\left(\text { gbest }_{\mathrm{i}}^{\mathrm{t}}-\mathrm{y}_{\mathrm{i}}^{\mathrm{t}}\right)
$$

And

$\mathrm{y}_{\mathrm{i}}^{\mathrm{t}+1}=\mathrm{y}_{\mathrm{i}}^{\mathrm{t}}+\mathrm{v}_{\mathrm{i}}^{\mathrm{t}+1}$

where

$\mathrm{a}_{\mathrm{i}}^{\mathrm{t+1}}$ is the velocity of particle

$\mathrm{y}_{\mathrm{i}}^{\mathrm{t}+1}$ is the present position of particle.

$\mathrm{y}_{\mathrm{i}}^{\mathrm{t}}$ is previous position of particle.

$\mathrm{y}_{\mathrm{i}}^{\mathrm{t}+1}$ is latest position of particle.

$\mathrm{S}$ is load factor

$Z_{1}, Z_{2}$ is learning coefficients, normally value (1-2) the variable produced randomly. Pbest ${ }_{i}{ }^{t}$ is the $P_{\text {best }}$, gbest $_{i}{ }^{t}$ is the $G_{\text {best }}$ 


\section{TABLE5.}

\begin{tabular}{|l|l|l|}
\hline S.no & parameters & value \\
\hline 1 & No of particles & 20 \\
\hline 2 & Min duty eycle & 0.01 \\
\hline 3 & Max duty eycle & 0.9 \\
\hline 4 & Samplingtime & 0.18 \\
\hline 5 & Maxiteration & 30 \\
\hline 6 & W min & 1 \\
\hline 7 & V max & 0.3 \\
\hline 8 & C1min & 0.1 \\
\hline 9 & C1 max & 1.05 \\
\hline 10 & C2min & 0.1 \\
\hline 11 & C2max & 1.05 \\
\hline
\end{tabular}

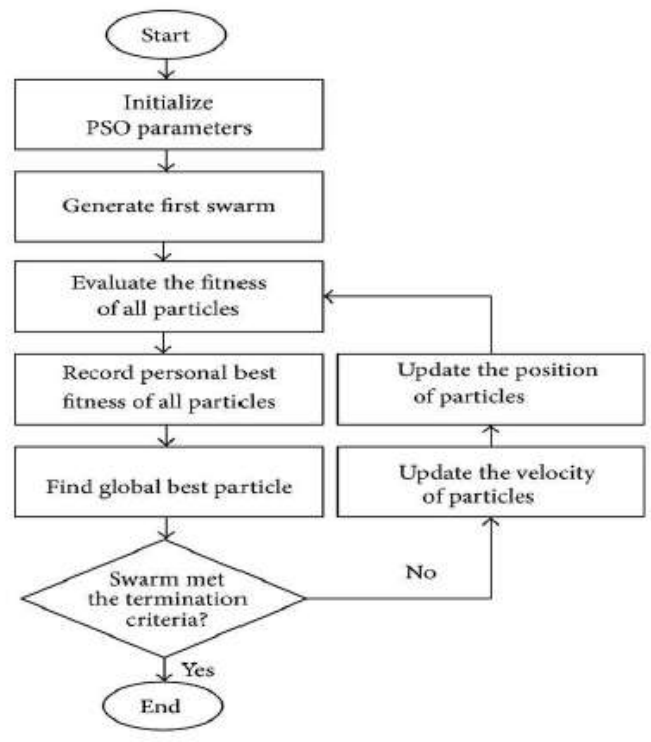

Fig15.

\section{PSO Algorithm Implementation}

- Set the velocity and position range when the parameters and particles in initialized.

- Every particle the velocity and position are initialized abruptly.

- For each particle the significance of $\mathrm{P}_{\text {best }}$ has been calculated.

- Gbest value has been set when the best value of the particle has been reached.

- The velocity and the position of values has been upgrade spontaneous depends on

the Gbest.

- Repeat the steps 3 and 4 up to the achieved optimal solution.

- The final optimized value has been decided at the last iteration based on Gbest.

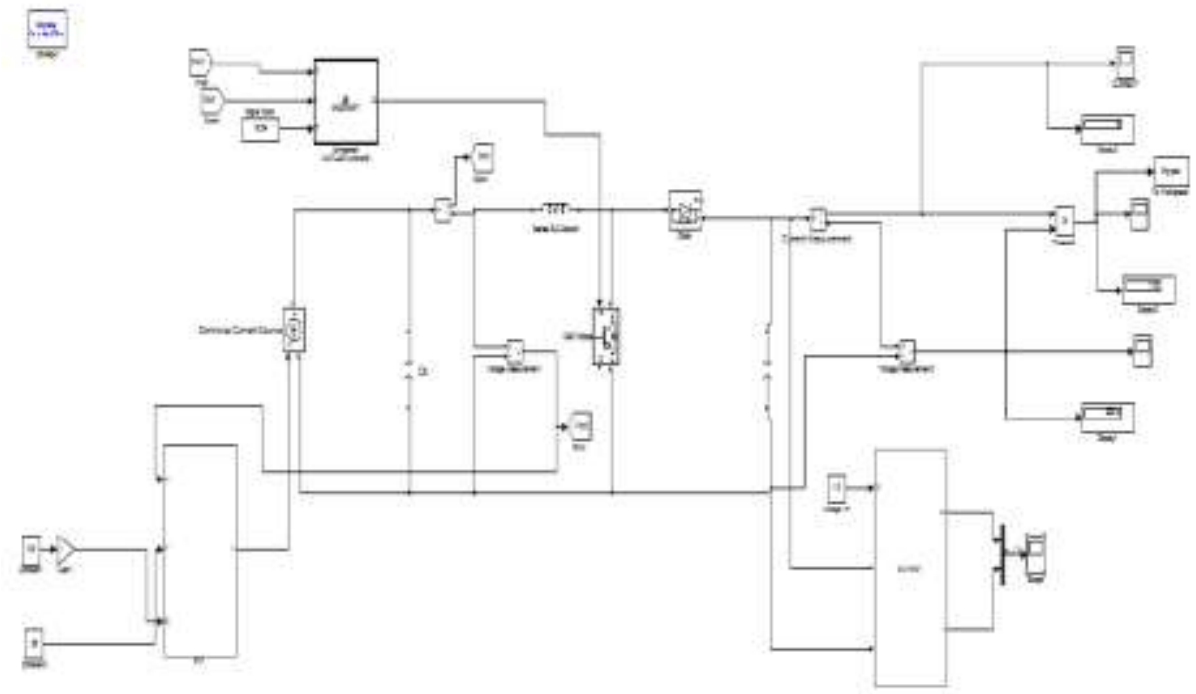

Fig16. Simulink of PSOMPPT system with DC motor pump load 
The PSO algorithm is subjected to upgrade the Duty cycle of Boost Converter by trace the global crest point with persistent upgrade the position and velocity. The Triggering pulse given to converter by using pulse width modulation technique used.

\section{DC-DC BOOST CONVERTER}

Boost converter is step up voltage or step down current from source to load. It consists of inductor, capacitor and switching devices. inductor is used boost up the voltage/limiting the current and capacitor is used as filter to suppress the voltage ripples normally added to converter output(load side filter) and input (source side filter). Switching devices are IGBT,MOSFET used for switching

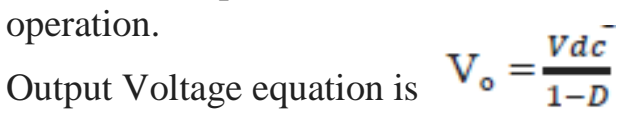

Where $\mathrm{D}$ (duty ratio) $\mathrm{D}=\mathrm{D}=\frac{T o n}{T}$

$\mathrm{T}_{\mathrm{on}}$ is the switching time and $\mathrm{T}$ is the switching period.

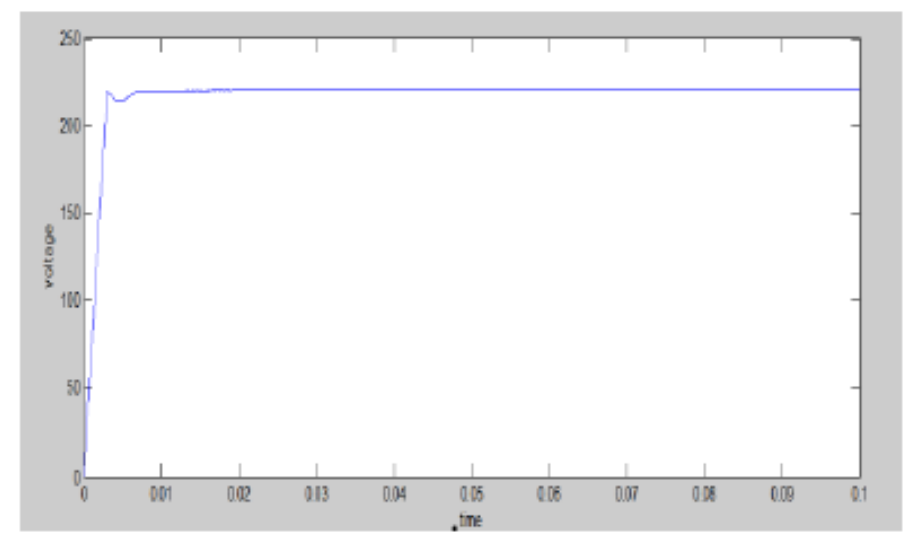

Fig17. Voltage waveform using psomppt

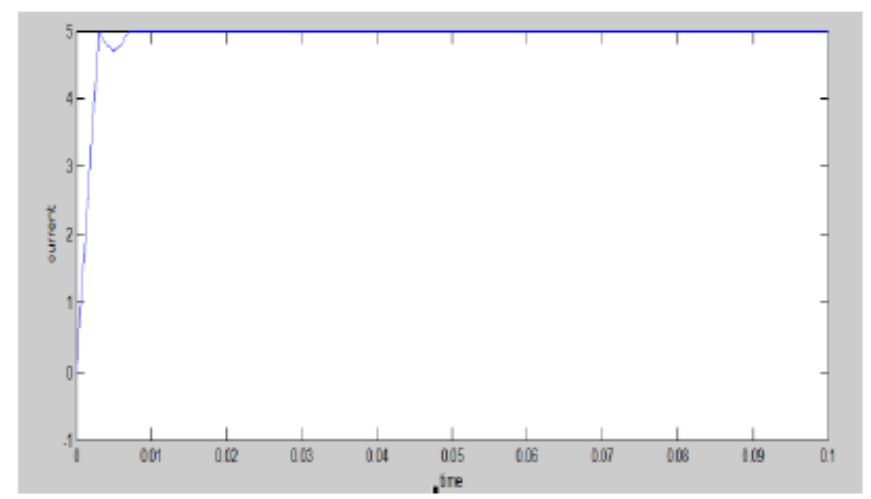

Fig18. Current waveform using psomppt

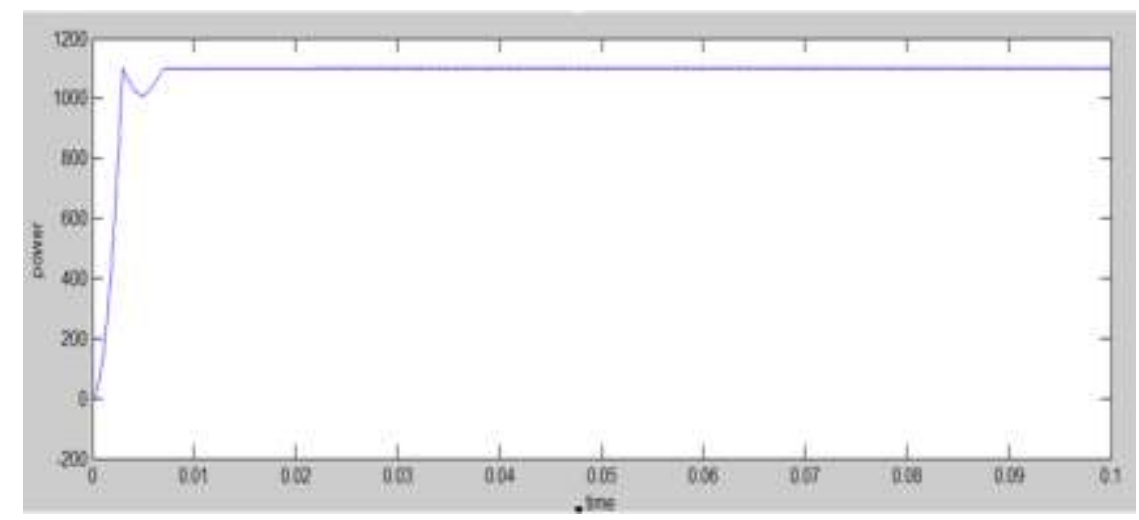

Fig19. Power wave form using psomppt 
Intelligent Algorithm based Maximum Power Point Tracking of Photovoltaic Solar Pump

Table 6. Pump performance during PSOMPPT coupling at constant irradiance levels and different temperature

\begin{tabular}{|l|l|l|l|l|}
\hline Irradiance $\left(\mathrm{W} / \mathrm{m}^{2}\right)$ & Temperature $\left({ }^{\circ} \mathrm{C}\right)$ & Motor speed (r.p.m) & Pump torque $(\mathrm{N}$ m) & Load power $(\mathrm{W})$ \\
\hline 600 & 25 & 933.0 & 4.546 & 843.5 \\
\hline 600 & 35 & 927.5 & 4.523 & 839.6 \\
\hline 600 & 40 & 921.2 & 4.495 & 835.3 \\
\hline 600 & 913.9 & 4.466 & 830.3 \\
\hline 600 & 50 & 905.2 & 4.43 & 824.4 \\
\hline 600 & 55 & 994.4 & 4.386 & 817.3 \\
\hline 600 & 980.3 & 4.329 & 808.2 \\
\hline 600 & 60 & 459.9 & 4.248 & 795.6 \\
\hline
\end{tabular}

Table7. Pump performance using PSOMPPT at constant temperature levels and different irradiance.

\begin{tabular}{|l|l|l|l|l|}
\hline Irradiance $\left(\mathrm{W} / \mathrm{m}^{2}\right)$ & Temperature $\left({ }^{\circ} \mathrm{C}\right)$ & Motor speed (r.p.m) & $\begin{array}{l}\text { Pump torque } \\
\mathrm{m})\end{array}$ & $(\mathrm{N}$ Load power $(\mathrm{W})$ \\
\hline 1000 & 25 & 1256 & 5.656 & 1102.2 \\
\hline 900 & 25 & 1242 & 5.583 & 1065.3 \\
\hline 800 & 1228 & 5.502 & 1045.4 \\
\hline 700 & 25 & 1212 & 5.413 & 1024.1 \\
\hline 600 & 25 & 1196 & 5.317 & 1001.5 \\
\hline 500 & 25 & 1176 & 5.216 & 1000.8 \\
\hline 400 & 1157 & 5.12 & 987 \\
\hline 300 & 25 & 1137 & 5.004 & 902 \\
\hline
\end{tabular}

\section{PMDC SOLAR PUMP}

Pmdc pump used perment magnet dc motor operated on dc supply. Permanent magnets are made of alnico and remaining construction same as dc motor. Here it is used as load running at constant speed[14].

Equivalent ckt of pmdc motor

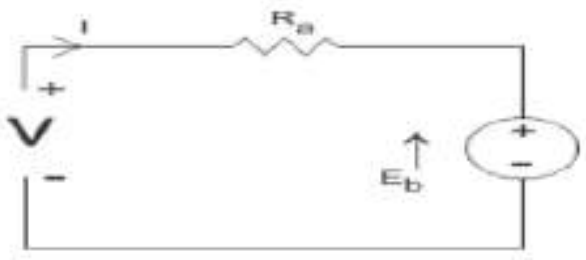

$\mathbf{V}=\mathbf{E}_{\mathbf{b}}+\mathbf{I}_{\mathbf{a}} \mathbf{R}_{\mathbf{a}}, \quad$ Back emf $\left(\mathrm{E}_{\mathrm{b}}\right)$, armature current $\left(\mathrm{I}_{\mathrm{a}}\right)$, armature resistance $\left(\mathrm{R}_{\mathrm{a}}\right)$

Pump is mechanical device movies the fluids from one place to another place by mechanical principal. In this classification centrifugal pumps[15] are operated only lower head, high discharge, poor suction of fluid and cavitations occurred. Positive displacement pumps have good suction power to lift the fluid, high head and low discharge. The submergible pumps are good suction, high head ,high discharge, not happen cavitations but corrosion problem and seal damage [18] is there in this pumps. Finally the proposed positive displacement pump used with a standalone water pumping system effectively. PMDC pump consumes less power and operated 110v dc as input voltage gives mechanical power as output. In this motor not required for field supply known as single excited system.

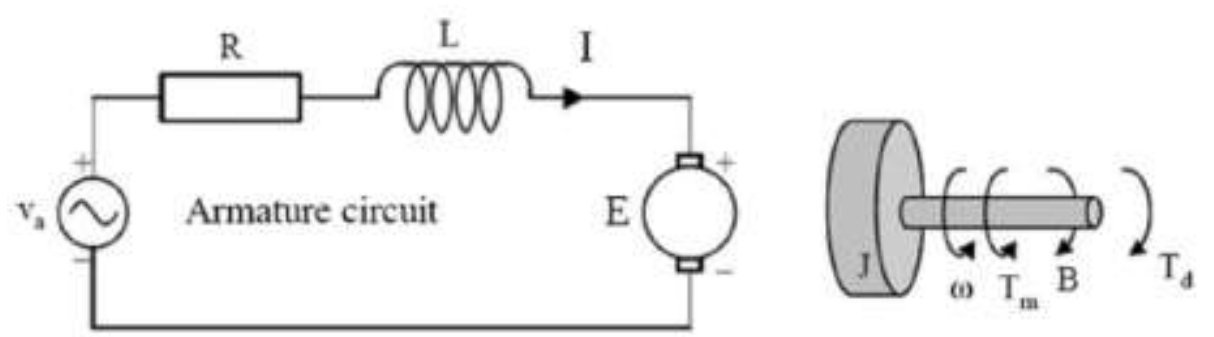

Fig20. $P M D C$ motor

International Journal of Research Studies in Electrical and Electronics Engineering (IJRSEE) Page | 33 
In a PMDC motor working principle is an armature conductors rotates inside a magnetic field. It experiences a force. The equations which describe the permanent magnet dc motor (PMDC) voltage and torque are given in Eqs. (13) and (14) respectively. Also, the positive displacement pump load equation is given as in Eq. (15) (from[17]).

$$
\begin{aligned}
& \mathrm{V}_{\mathrm{a}}=\mathrm{I}_{\mathrm{a}} \mathrm{R}_{\mathrm{a}}+\mathrm{L}_{\mathrm{a}} \frac{d I \mathrm{a}}{d t}+\mathrm{K}_{3} \omega \\
& \mathrm{T}=\mathrm{A}_{3}+\mathrm{B}_{1} \omega+\mathrm{J} \frac{d \omega}{d t}+\mathrm{T}_{\text {load }} \\
& \mathrm{T}_{\text {load }}=\mathrm{A}_{1}+\mathrm{C} \omega^{1.8}
\end{aligned}
$$

$\mathrm{V}_{\mathrm{a}}$ is armature voltage(V), Ia armature current(A), $\mathrm{l}_{\mathrm{a}}$ inductance of armature $(\mathrm{H}), \mathrm{K}_{3}$ backemf constant $(\mathrm{NM} / \mathrm{A}), \mathrm{R}_{\mathrm{a}}$ resistance of armature $(\Omega), \mathrm{T}$ is motor torque $(\mathrm{Nm}), \mathrm{A}_{3}$ friction constant $(\mathrm{Nm}), \mathrm{B}_{1}$ damping constant $(\mathrm{Nms} / \mathrm{rad}), \mathrm{J}$ inertia of rotor $\left(\mathrm{kgm}^{2}\right), \mathrm{T}_{\text {load }}$ load torque $(\mathrm{Nm}), \mathrm{A}_{1}$ friction constant $(\mathrm{Nm})$, $\in$ constant of load torque( $\mathrm{Nms} / \mathrm{rad})$.

The solar water pump supplies an amount of water that is dependent on the power supplied to the pump, total dynamic head and the efficiency of the pump

$$
\eta_{\mathrm{p}}=\frac{\rho g h Q}{I V}
$$

where $\eta p$ is the total efficiency of pump, I is the supply current to the pump, $\mathrm{V}$ is the supply voltage to the pump, $\rho$ is the density of water, $\mathrm{g}$ is the acceleration due to gravity, $\mathrm{h}$ is the total head, $\mathrm{Q}$ is the volume flow rate of water.

\section{CONCLUSION}

This paper introduced a study of psomppt controller connected pv systems to run the pmdc pump effectively at different temperature and irradiation .first design $\mathrm{pv}$ module based single diode $\mathrm{R}_{\mathrm{p}}$ model with matching datasheet. Psomppt get good output power compared to ANFIS controller done by MATLAB.

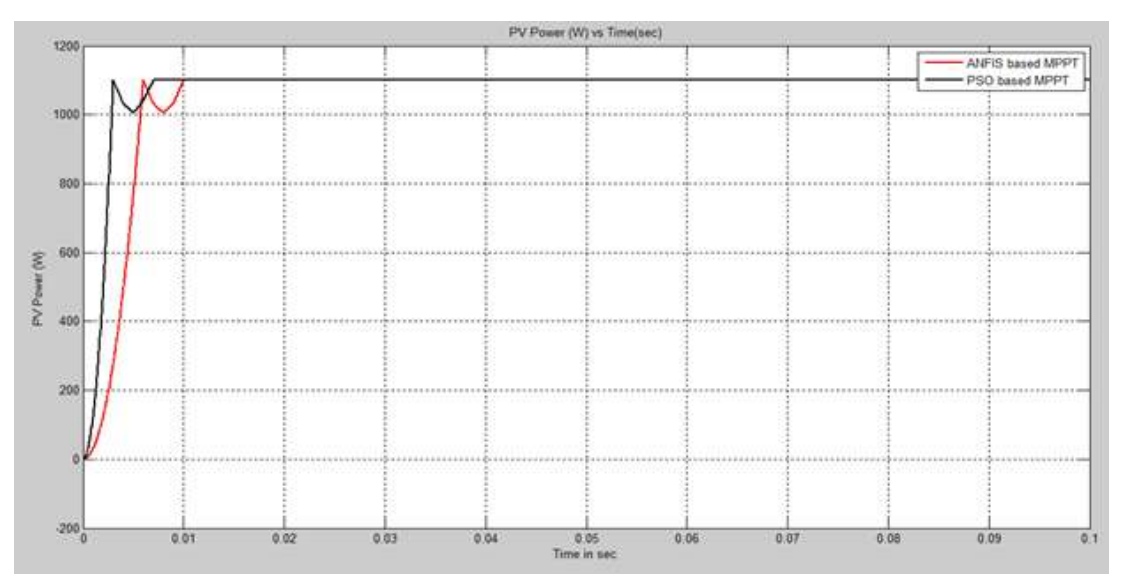

The psomppt should matching impedance from pv module as source to pmdc pump as load for maximum power transfer by controlling duty ratio of boost converter. Psomppt algorithm simulation should achieved maximum power, fast response, less number of oscillations and gain in the output power is high at environmental conditions. PSOMPPT response has less settling time and peak overshoot comparing to ANFIS. PSOMPPT controller has some benefits over some other controller they are listed as follows, Simple structure, Easy Execution and has a very fast convergence speed to the preferred solution and it has very high tracking speed.

\section{REFERENCES}

[1] M.K.Alam,F.H.Khan and A.S.Imtiaz, "An efficient power electronics solution for lateral multi junction solar cell systems," in Proc.IEEE IECON,pp.4373-4378,2011.

[2] L.Zhao,"High Efficiency Mechanically Stacked Multi-Junction Solar Cells for Concentrator Photovoltaics",Ph.D.dissertation,KatholiekeUniversity,LeuvenFaculteit,Ingenieurswetenschappen,Arenbergkast eel,Belg ium, Mar. 2011.

International Journal of Research Studies in Electrical and Electronics Engineering (IJRSEE) Page | 34 
[3] L. Gao, R. A. Dougal, S. Liu, and A. P. Iotova, "Parallel-connected solarPV system to address partial and rapidly fluctuating shadow conditions," IEEE Trans. Ind. Electron., vol. 56, no. 5, pp. 1548-1556, May 2009 .

[4] M.Meinhardt,G.Cramer,B.Burger,and P.Zacharias, "Multi-string converter with reduced specific costs and enhanced functionality,’Solar Energy,vol.69(Suppl.),n0.1-6,pp.217-227,2000.

[5] Prakash J, Sarat Kumar Sahoo, S.Prabhakar Karthikeyan and I.Jacob Raglend "Design Of PSO- Fuzzy MPPT Controller for Photovoltaic Application," International Conference on Artificial Intelligence and Evolutionary Algorithms in Engineering Systems, pp.1339-1348, 2014.

[6] Karami, Nabil, Moubayed, Nazih, Outbib, Rachid, 2017. General review and classification of different MPPT techniques. Renew. Sustain. EnergyRev. 68 (February (Part 1)), 1-18.

[7] Kikolski, Mateusz, 2017. Study of production scenarios with the use of simulation models. Procedia Eng. $182,321-328$.

[8] KC200GT solar cell data sheet. Online Available http://store.affordable-solar.com/store/discontinuedunavailable- solar-panels/kyocera-kc200gt-200watt-solar-panel. (Accessed 15 August 2017).

[9] Rezakazemi, Mashallah, Dashti, Amir, Asghari, Morteza, Shirazian, Saeed, 2017. H2-selective mixed matrix membranes modeling using ANFIS,PSO-ANFIS, GA-ANFIS. Int. J. Hydrogen Energy 42 (June (22)), 15211-15225.

[10] Abolfazl Hosseini, Seyed, Paeen Afrakoti, Iman Esmaili, 2017. Neutron noise source reconstruction using the adaptive neuro-fuzzy inference system(ANFIS) in the VVER-1000 reactor core. Ann. Nucl. Energy 105 (July), 36-44.

[11] W Razia Sultana, Sarat Kumar Sahoo, Prabhakar Karthikeyan, Jacob Raglend, Harsha Vardhanreddy and Rajasekhar Reddy "Elimination of harmonics in multilevel inverter using Particle Swarm Algorithm as an Optimization Technique," International Conference on Artificial Intelligence and Evolutionary Algorithms in Engineering Systems, pp.265-274, 2014.

[12] J. Prakash, Sarat Kumar Sahoo " Modeling of photovoltaic system and design of MPPT controller using PSO algorithm," International conference on Environment \& energy ,pp.36-41, 2013.

[13] Periasamy, Packiam, Jain, N.K., Singh, I.P., 2015. A review on development of photovoltaic water pumping system. Renew. Sustain. Energy Rev.43 (March), 918-925.

[14] Sontake, Vimal Chand, Kalamkar, Vilas R., 2016. Solar photovoltaic water pumping system-a comprehensive review. Renew. Sustain. Energy Rev.59 (June), 1038-1067.

[15] Chandel, S.S., Nagaraju Naik, M., Chandel, Rahul, 2017. Review of performance studies of direct coupled photovoltaic water pumping systems andcase study. Renew. Sustain. Energy Rev. 76 (September), 163175.

[16] Fawzy El-Khatib, Mohamed, Shaaban, S., Abu El-Sebah, Mohamed I., 2017. A proposed advanced maximum power point tracking control for aphotovoltaic-solar pump system. Solar Energy 158 (December), 321-331.

[17] Ibrahim, H.E.A., Ibrahim, Mahmoud, 2013. MPPT using fuzzy controller for photovoltaic pumping system. In: IEEE International Conference onControl Engineering and Communication Technology (ICCECT), December, pp. 150-155.

[18] Llorente, J.G., Eduardo, I., Rivera, O., Llinas, A.S., Brea, E.J., 2010. Analyzing the optimal matching of dc motors to photovoltaic modules via dc-dc converters. In: Applied Power Electronics Conference and Exposition (APEC), 2010 Twenty-Fifth Annual IEEE. IEEE, pp. 1062-1068.

[19] Balamurugan.M1, Narendiran.S1, Sarat Kumar Sahoo1, Raja Das2, Ashwin Kumar Sahoo3 School of Electrical Engineering, VIT University, Vellore, India Application of Particle Swarm Optimization for Maximum Power Point Tracking in PV System

Citation: B.Hari Sankar Reddy \& K. Nagabhushanam (2019). Intelligent Algorithm based Maximum Power Point Tracking of Photovoltaic Solar Pump. International Journal of Research Studies in Electrical and Electronics Engineering (IJRSEE), 5(3), pp.23-35. http://dx.doi.org/10.20431/2454-7999.0503004

Copyright: (c) 2019Authors, this is an open-access article distributed under the terms of the Creative Commons Attribution License, which permits unrestricted use, distribution, and reproduction in any medium, provided the original author and source are credited. 